\title{
ICP-AES Characterization of PHWR Irradiated Thoria Bundles for Fission Products
}

\author{
Arijit Sengupta*, B. Rajeswari, V.C. Adya, and R.M. Kadam \\ Radiochemistry Division, Bhabha Atomic Research Centre, \\ Mumbai, India
}

\section{INTRODUCTION}

The current generation of Pressurized Heavy Water Reactor (PHWR) fuels have been highly optimized for the traditional PHWR fuel cycles (1-3). Thorium-based fuels have been studied for their potential applications in almost all types of reactors including Pressurized Water Reactors (PWRs), Boiling Water Reactors (BWRs), PHWRs, High Temperature Reactor (HTRs), Fast Breeder Reactors (FBRs) and Molten Salt Reactors (MSRs), though on a small scale compared to U/U-Pu fuels (4-7). With a view to address the suitability and potential advantages of a thorium-based nuclear system to perform full actinide recycling with transuranic isotopes burning, it is necessary to characterize the irradiated thoria bundles for its fission product contents.

Thoria bundles, which have been irradiated in PHWRs, are being taken up for reprocessing in the Power Reactor Thoria Reprocessing Facility (PRTRF), Bhabha Atomic Research Centre, Mumbai, India. To generate data from this thoria fuel for understanding reactor physics, analytical data such as total $\mathrm{U}$ and Th content, isotopic composition of generated $\mathrm{U}$, individual contents of fission products and minor actinides are inevitable for understanding the irradiation history, and thereby calculation of burn-up data of thoria bundles. In this context, efforts were put towards analyzing five solutions supplied by PRTRF for their fission product and Th contents using inductively coupled plasma atomic

\footnotetext{
${ }^{*}$ Corresponding author.
}

E-mail: arijita@barc.gov.in

\begin{abstract}
A methodology was optimized for the determination of fission products in irradiated thoria. Chlorinated cobalt dicarbollide (CCD) and tri-n-butyl phosphate (TBP) were employed for the separation of $\mathrm{U}$ and $\mathrm{Th}$, respectively, for dose reduction and to avoid spectral interferences arising out of the emission rich spectra of $\mathrm{U}$ and $\mathrm{Th}$. The tolerance level of $U$ and Th on these analytes was found to be $100 \mathrm{mg} \mathrm{L}^{-1}$ and $125 \mathrm{mg} \mathrm{L}^{-1}$, respectively. Five contacts of TBP were required for preferential separation of $U$ and Th. CCD formed a $\mathrm{Cs}^{+} \mathrm{CCD}^{-}$ complex through an 'ion exchange' mechanism, while TBP formed $\mathrm{UO}_{2}\left(\mathrm{NO}_{3}\right)_{2} \cdot 2 \mathrm{TBP}$ and $\mathrm{Th}\left(\mathrm{NO}_{3}\right)_{4} \cdot 3 \mathrm{TBP}$ complexes through a 'solvation' mechanism.
\end{abstract}

emission spectrometry (ICP-AES) with a glove box-adapted facility for handling radioactive samples. In view of its high sensitivity, good precision, large linear dynamic range, relative freedom from matrix effects, and its capability to provide relatively low detection limits for the simultaneous determination of common as well as rare earth impurities in different matrices, ICP-AES has been routinely used for trace metallic characterization of nuclear materials (8-15). However, the commercially available ICP emission spectrometers cannot be readily employed for the analysis of ${ }^{239} \mathrm{Pu}$ and ${ }^{233} \mathrm{U}$ based nuclear fuels due to their inadaptability to handle radiotoxic materials. Moreover, the presence of emission-rich actinides in the samples leads to erronious results due to the spectral interference and hence, required preferential chemical separation (16-20).

\section{EXPERIMENTAL}

All of the atomic emission spectrometric studies were carried out using a Jobin-Yvon Ultima high resolution ICP-AES (Jobin Yvon, Longjumeau, France). It has the practical resolution of $\leq 0.005 \mathrm{~nm}$ and a spectral range of $180-800$ $\mathrm{nm}$. The operating conditions are chosen based on our previous reports (20) and are listed in Table I.

TABLE I

Specification and Experimental Parameters for ICP-AES Instrument

\begin{tabular}{lr}
\hline Optical Design & Czerny Turner \\
Grating & Holographic \\
Groove density & $2400 / \mathrm{mm}$ \\
Range of wavelength & $120-800 \mathrm{~nm}$ \\
Radiofrequency & $40.68 \mathrm{MHz}$ \\
Nebulizer & Pneumatic \\
Ar gas flow & $12 \mathrm{~L} \mathrm{~min}^{-1}$ \\
Sample flow rate & $1 \mathrm{~mL} \mathrm{~min}^{-1}$ \\
\hline
\end{tabular}

\section{Reagents and Standard Solutions}

Rare earth elements and other common impurity standard solutions were prepared from high purity solutions (E. Merck, Darmstadt, Germany) by suitable dilutions with $0.5 \mathrm{M} \mathrm{HNO}_{3}$. Suprapur ${ }^{\circledR}$ (E. Merck) $\mathrm{HNO}_{3}$ and quartz double-distilled water were used for preparing $0.5 \mathrm{M} \mathrm{HNO}_{3}$. The calibration plots for each analyte were obtained by using multiple standards having analyte concentrations in the $0-100 \mu \mathrm{g} / \mathrm{mL}$ range. This method consisted of creating an analytical method for choosing the required fission products, profiling, peak searching, and auto-attenuation of each analyte element, followed by optimization of the working parameters, calibration of 
working standards and finally, analysis of the samples in quadruplicate to establish reasonably good precision. Since the solutions received from PRTRF had a high dose radioactivity (approx. 600 $\mathrm{mR} / \mathrm{hr}$ ) due to the presence of ${ }^{137} \mathrm{Cs}$, the latter was separated from these solutions using 0.1 M CCD (chlorinated cobalt dicarbollide) extractant in FS-13 (phenyl trifluoromethyl sulfone) diluent, thereby bringing down the dose of both solutions into the workable level of $20 \mathrm{mR} / \mathrm{hr}$ (21-23). Further, the major matrix elements, namely 'Th' and ' $U$ ', which are bound to cause spectral interference with the analyte detection, were separated by solvent extraction using three contacts of 30\% TBP in Xylene/3M $\mathrm{HNO}_{3}$ system $(24,25)$. The residual (raffinate) solution after separation of $U$ and Th was aspirated into the plasma for the determination of potentially important fission products present in the solutions. Three solutions, which were less active and not containing $\mathrm{U}$ or Th, were directly analyzed by the ICP-AES. To estimate the Th content in the dissolver and $1 \mathrm{AF}$ solutions (both contain Th at \% level), direct aliquots were appropriately diluted and estimated in the ICP-AES.

TBP and n-dodecane were procured from Koch-Light Laboratories, USA, and Lancaster, UK, respectively. The TBP solution was washed with $5 \% \mathrm{Na}_{2} \mathrm{CO}_{3}$ to remove the acidic impurities. The FS-13 and CCD were obtained from Marshallton Research Laboratories (King, NC, USA). Figure 1 represents the structures of CCD, FS 13, and TBP used in the present investigation.

\section{RESULTS AND DISCUSSION}

\section{Optimization of Separation Procedure}

The distribution ratio values for $\mathrm{Cs}^{+}\left(\mathrm{D}_{\mathrm{Cs}}\right)$ were varied as a function of aqueous feed acidity because the feed acidity plays a significant role in the extraction efficiency of dif-

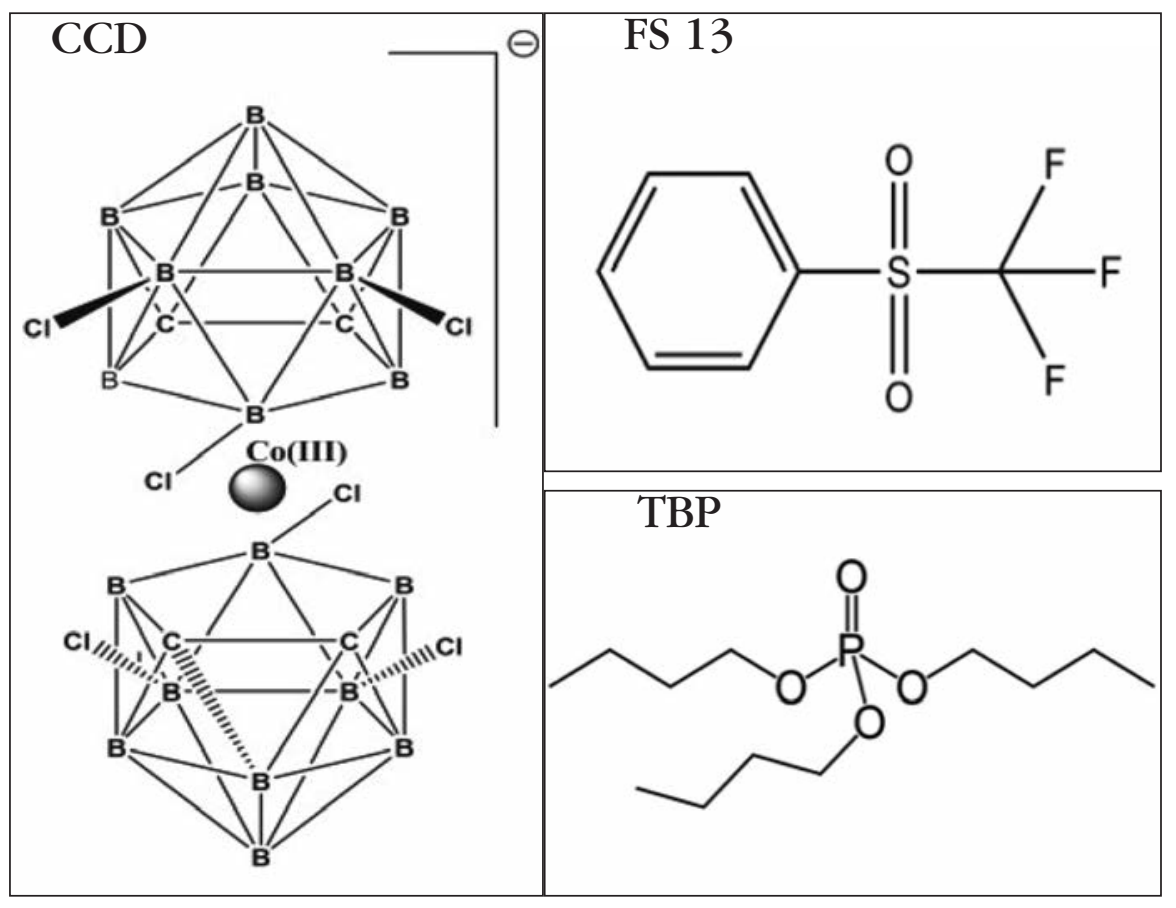

Fig. 1.Structure of CCD, FS 13, and TBP. ferent metal ions. In the present case, the $\mathrm{D}_{\mathrm{Cs}}$ value was found to be $\sim 800$ from $0.01 \mathrm{M} \mathrm{HNO}_{3}$ solution and this $\mathrm{D}_{\mathrm{Cs}}$ value was found to decrease drastically up to $3 \mathrm{M}$ $\mathrm{HNO}_{3}$, followed by only moderate decrease. This type of extraction profile revealed the predominance of the ion exchange mechanism shown by the following equation:

$$
\begin{aligned}
& \mathrm{Cs}^{+}{ }_{\text {aq }}+\mathrm{nH}^{+} \mathrm{CCD}^{-}{ }_{\text {org }}= \\
& \mathrm{Cs}^{+} \cdot \mathrm{nCCD}^{-}{ }_{\text {org }}+\mathrm{nH}^{+}{ }_{\text {aq }}
\end{aligned}
$$

(Eq. 1)

where 'aq' and 'org' represented the aqueous and organic phase, respectively. At higher feed acidity, the backward reaction is favored, therefore the $D_{C s}$ value reduced. ' $n$ ' is the number of CCD moieties attached to the $\mathrm{Cs}^{+}$ion. The equilibrium constant for the above equation can be expressed as:

$$
\mathrm{K}_{\mathrm{ex}}=\frac{\left(\mathrm{Cs}^{+} \cdot \mathrm{nCCD}^{-}{ }_{\left.{ }_{\text {org }}\right]\left[\mathrm{H}^{+}{ }_{\mathrm{ag}}\right]^{\mathrm{n}}}\right.}{\left[\mathrm{Cs}^{+}{ }_{\mathrm{aq}}\right]\left[\mathrm{H}^{+} \mathrm{CCD}^{-}{ }_{\text {org }}\right]^{\mathrm{n}}}
$$

At a particular temperature and feed acidity the equation can be simplified as:

$$
\mathrm{K}_{\mathrm{ex}}^{,}=\frac{\mathrm{D}_{\mathrm{cs}}}{\left[\mathrm{H}^{+} \mathrm{CCD}^{-}{ }_{\text {org }}\right]^{\mathrm{n}}}
$$

(Eq. 3)

$\mathrm{K}_{\text {ex }}^{\prime}$ is the conditional extraction constant. After taking the logarithm of both sides of Equation 3, followed by rearrangement led to the equation as follows:

(Eq. 4)

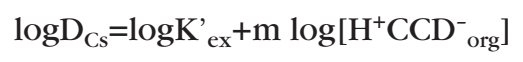

A plot of $\log \mathrm{D}_{\mathrm{Cs}}$ vs $\log \mathrm{CCD}$ concentration gave a straight line with a slope $\sim 1$ suggesting that one CCD molecule is attached to the $\mathrm{Cs}^{+}$ion (Figure 2). The change in Gibb's free energy (26-27) during the extraction was evaluated as $-18.84 \mathrm{~kJ} \mathrm{~mol}^{-1}$ revealing the spontaneity of the extraction process (Table I). This study revealed that higher feed acidity was not suitable 


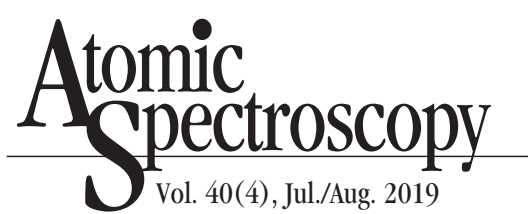

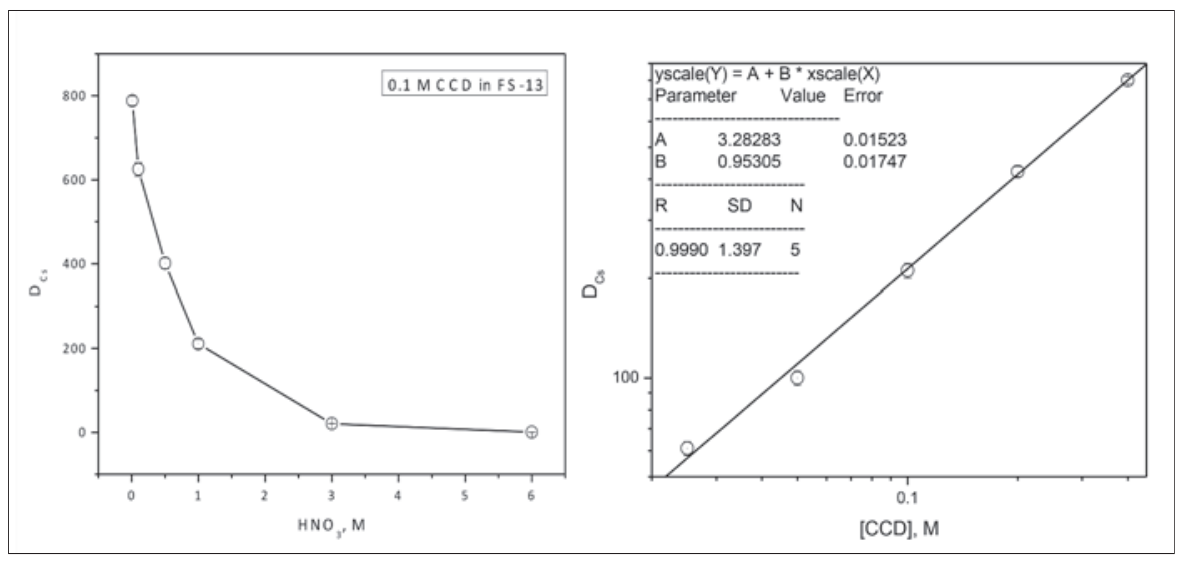

Fig. 2. The variation of $D_{C s}$ value as a function of (a) feed acidity and (b) concentration of CCD.

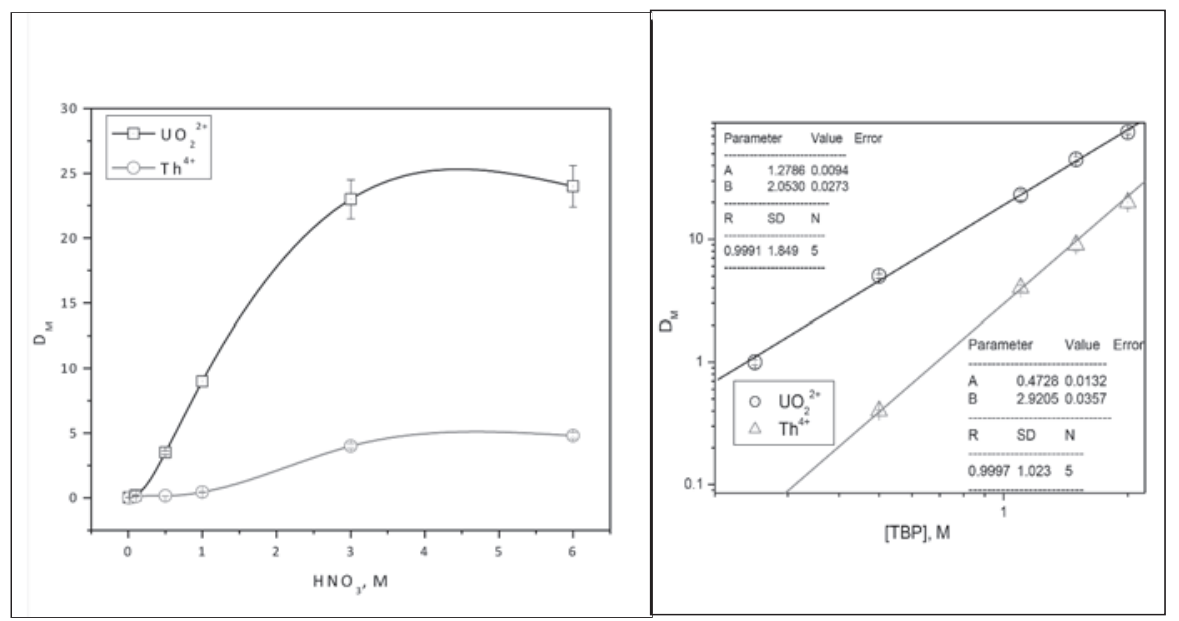

Fig. 3. Variation of $D_{U}$ and $D_{T b}$ value as a function of (a) feed acidity and (b) concentration of TBP.

for the extraction of Cs; therefore, $1 \mathrm{M} \mathrm{HNO}_{3}$ was taken to serve the purpose with a $\mathrm{D}_{\mathrm{Cs}} \sim 200$.

Similarly, to optimize the method, the $\mathrm{D}$ values for $\mathrm{Th}^{4+}$ and $\mathrm{UO}_{2}{ }^{2+}$ were varied as a function of aqueous feed acidity. Generally, actinides are multi-electronic systems and, therefore, have multiple lines in their emission spectra. The presence of these elements thus may lead to erroneous determination of other analytes present at the trace level due to their spectral interference. To avoid such circumstances, $\mathrm{U}$ and Th need to be separated from the samples without loss of other impurities. To serve the purpose, 30\% TBP in xylene was employed. The $\mathrm{D}_{\mathrm{U}}$ and $\mathrm{D}_{\mathrm{Th}}$ values were found to increase with an increase in aqueous feed acidity, followed by a plateau, suggesting the predominance of a solvation mechanism.

A similar approach was adopted to find out the metal-ligand stoichiometries for the present case. The $\mathrm{UO}_{2}{ }^{2+}$ was found to form a 1:2 complex with TBP in xylene, whereas $\mathrm{Th}^{4+}$ formed a 1:3 complex (Figure 3 ). Both extraction processes were found to be thermodynamically favorable as suggested by the negative $\Lambda G$ values. Based on the studies, it was decided that though the
TABLE II

Determination of Metal-Ligand Stoichiometry, Conditional Extraction Constants, and Change in Gibb's Free Energy for the Extraction Processes

\begin{tabular}{lccc}
\hline Metal & $\mathrm{M}: \mathrm{L}$ & $\mathrm{K}^{\prime}{ }_{\mathrm{ex}}$ & $\begin{array}{l}\Lambda \mathrm{G}(\mathrm{kJ} \\
\left.\mathrm{mol}^{-1}\right)\end{array}$ \\
\hline $\mathrm{UO}_{2}{ }^{2+}$ & $1: 2$ & 19.1 & -7.35 \\
$\mathrm{Th}^{4+}$ & $1: 3$ & 2.95 & -2.70 \\
$\mathrm{Cs}^{+}$ & $1: 1$ & 1905 & -18.84 \\
\hline
\end{tabular}

$1 \mathrm{M} \mathrm{HNO}_{3}$ feed was found to be sufficient for the selective and efficient removal of $\mathrm{Cs}^{+}$, the feed acidity was to be readjusted to $3 \mathrm{M}$ $\mathrm{HNO}_{3}$ for the selective separation of $\mathrm{U}$ and $\mathrm{Th}$.

(Eq. 5)

$$
\begin{aligned}
& \mathrm{UO}_{2}{ }^{2+}{ }_{\mathrm{aq}}+2 \mathrm{TBP}_{\mathrm{org}}+2 \mathrm{NO}_{3}^{-} \mathrm{aq} \\
& \mathrm{UO}_{2}\left(\mathrm{NO}_{3}\right)_{2} \cdot 2 \mathrm{TBP} \\
& \text { (Eq. 6) } \\
& \mathrm{Th}^{4+}{ }_{\mathrm{aq}}+3 \mathrm{TBP}_{\mathrm{org}}+4 \mathrm{NO}_{3}^{-}{ }_{\mathrm{aq}}= \\
& \mathrm{Th}\left(\mathrm{NO}_{3}\right)_{3} \cdot 4 \mathrm{TBP}
\end{aligned}
$$

\section{Evaluation of Analytical Perfor- mance for the Considered Ana- lytical Lines in ICP-AES}

Before analyzing the actual samples, it was necessary to choose the analytical lines of the elements, which shows the desired analytical performance such as lower detection limits, higher sensitivity, and good precision. For the present investigation, the $\mathrm{Ba} 455.403 \mathrm{~nm}$, Ce 413.765 nm, Eu 420.505 nm, Gd $379.639 \mathrm{~nm}, \mathrm{La} 408.671 \mathrm{~nm}$, Mo $202.030 \mathrm{~nm}, \mathrm{Nd} 401.225 \mathrm{~nm}$, Pr $414.311 \mathrm{~nm}, \operatorname{Sm} 359.262 \mathrm{~nm}$, Sr $407.771 \mathrm{~nm}, \mathrm{Y} 371.029 \mathrm{~nm}$, Th $401.913 \mathrm{~nm}$, and U $385.958 \mathrm{~nm}$ analytical lines were chosen for their determination. The slope values for the calibration curves were determined as the sensitivity of the analytical lines. The concentration corresponding to the intensity equivalent to the blank + three times the relative standard deviation was evaluated as the detection limits for the analytes using the 
mentioned lines. The \% RSD values were found to be well below 5\% revealing the reproducibility of the results due to the highly stable excitation source. The detection limits for all these analytical lines were found to be below $0.1 \mathrm{mg} \mathrm{L}^{-1}$, while the sensitivity values were found to be more than $\mathrm{E}+02$. Table III summarizes the analytical performance of the emission lines of the different analytes.

\section{Evaluation of Number of Contacts}

In optimizing the separation process, it is required to know the number of contacts of TBP-xylene required to reduce the $\mathrm{U}$ and $\mathrm{Th}$ concentration below a certain level (U: $100 \mathrm{mg} \mathrm{L}^{-1}$, Th: $125 \mathrm{mg} \mathrm{L}^{-1}$ ) to avoid spectral interference. Obviously, the number of steps depends on the initial concentration of $U$ and Th. The initial concentrations for $T h$ and $U$ were chosen as $\sim 25000 \mathrm{mg} \mathrm{L}^{-1}$ and $1000 \mathrm{mg} \mathrm{L}^{-1}$, respectively. It was observed that only after five contacts, the Th concentration on the raffinate became less than the tolerance level, while for $U$ after two contacts the same can be achieved. Therefore, based on this study, five contacts were chosen for the simultaneous removal of $U$ and $T h$ from the analytes even at the trace level. Figure 4 shows the concentration of $U$ and Th after each contact of TBP-xylene.

\section{Determination of the Analytes in Dissolver Solutions of PHWR Irradiated Thoria}

Five different samples (named as dissolver, 1CP, 1AF, UST1, and UST2) of dissolver solution, generated from PHWR irradiated thoria bundles, were analyzed using the following scheme as optimized earlier (Figure 5). The dissolver solution is the solution obtained after dissolving the irradiated thoria fuel assembly in $\mathrm{HF}-\mathrm{HNO}_{3}$ mixture. $1 \mathrm{CP}, 1 \mathrm{AF}$, UST1, and UST2 refer either to different positions of irradiation per-

Table III

Analytical Performance of the Emission Lines of Different Analytes

\begin{tabular}{lcccc}
\hline Element & $\begin{array}{c}\text { Analytical Lines } \\
(\mathrm{nm})\end{array}$ & $\begin{array}{c}\text { Detection Limits } \\
\left(\mathrm{mg} \mathrm{L}^{-1}\right)\end{array}$ & $\begin{array}{c}\text { Sensitivity } \\
\left(\text { Counts } \mathrm{mg}^{-1} \mathrm{~L}\right)\end{array}$ & $\begin{array}{c}\text { RSD } \\
(\%)\end{array}$ \\
\hline $\mathrm{Ba}$ & 455.403 & 0.04 & $1.03 \mathrm{E}+04$ & 1.95 \\
$\mathrm{Ce}$ & 413.765 & 0.1 & $9.90 \mathrm{E}+02$ & 2.94 \\
$\mathrm{Eu}$ & 420.505 & 0.07 & $7.36 \mathrm{E}+02$ & 1.18 \\
$\mathrm{Gd}$ & 379.639 & 0.08 & $1.11 \mathrm{E}+03$ & 0.88 \\
$\mathrm{La}$ & 408.671 & 0.09 & $9.67 \mathrm{E}+02$ & 3.09 \\
$\mathrm{Mo}$ & 202.03 & 0.06 & $1.13 \mathrm{E}+03$ & 4.73 \\
$\mathrm{Nd}$ & 401.225 & 0.07 & $9.55 \mathrm{E}+02$ & 0.44 \\
$\mathrm{Pr}$ & 414.311 & 0.05 & $9.47 \mathrm{E}+02$ & 2.1 \\
$\mathrm{Sm}$ & 359.262 & 0.07 & $9.14 \mathrm{E}+02$ & 1.98 \\
$\mathrm{Sr}$ & 407.771 & 0.05 & $9.84 \mathrm{E}+03$ & 2.48 \\
$\mathrm{Y}$ & 371.029 & 0.04 & $1.15 \mathrm{E}+04$ & 0.23 \\
$\mathrm{Th}$ & 401.913 & 0.07 & $2.45 \mathrm{E}+03$ & 3.39 \\
$\mathrm{U}$ & 385.958 & 0.1 & $1.17 \mathrm{E}+03$ & 2.74 \\
\hline
\end{tabular}

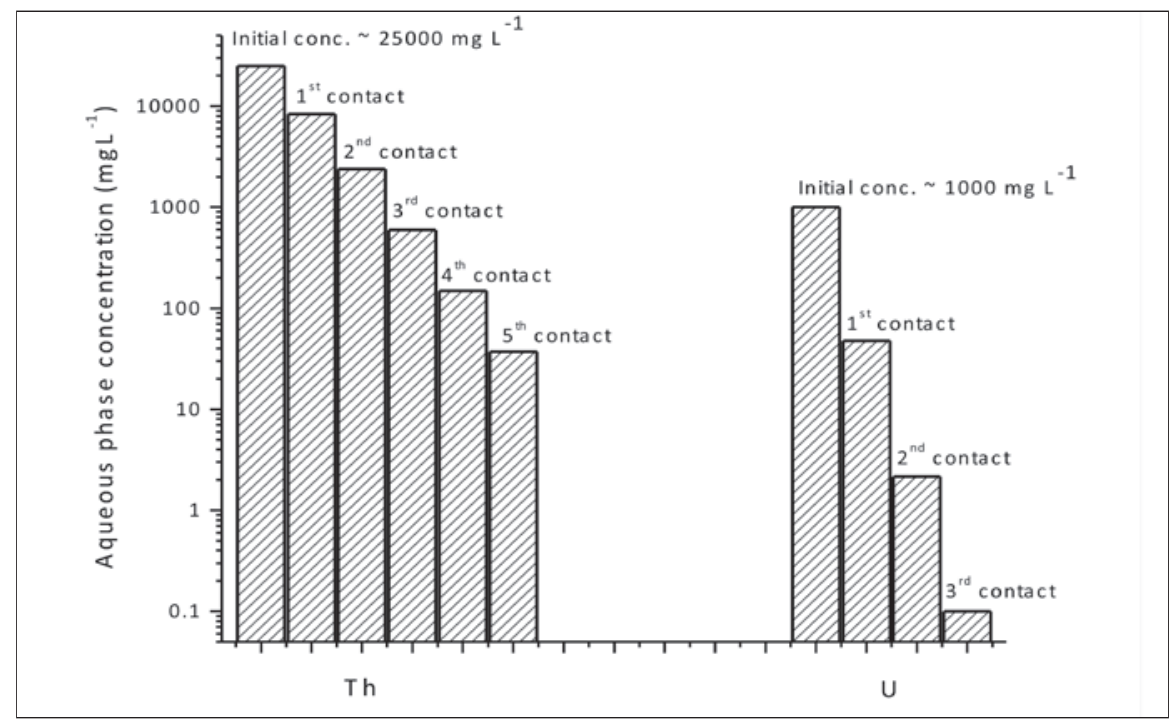

Fig. 4. Concentration of $U$ and Th in the raffinate after each contact of TBP-xylene.

taining to a different neutron flux in the reactor, or it can be at different times of irradiation. The exact source cannot be revealed due to the confidential nature.

The very high gamma dose of the samples was reduced by preferential separation of ${ }^{137} \mathrm{Cs}$ by $0.1 \mathrm{M}$ CCD in FS 13 from $1 \mathrm{M} \mathrm{HNO}_{3}$ feed acidity. Then the sample acidity was adjusted to $3 \mathrm{M} \mathrm{HNO}_{3}$ for preferential separation of $\mathrm{U}$ and $\mathrm{Th}$ using 30\% TBP in xylene. Table IV summarizes the analytical results obtained. The method was validated using synthetic samples. Since standard reference materials for such radioactive origin is not available commercially in national or international levels, a synthetic sample is one of the few choices to validate the method. Since these samples involve high level of radioactivity, other suitable analytical techniques for the determination of such multi-elements in one 
stretch is practically impossible. The Th and U contents were determined by stripping the organic phase with $5 \% \mathrm{Na}_{2} \mathrm{CO}_{3}$ and feeding the same into the plasma. A $1 \mathrm{CP}$ solution was found to contain Ce and Gd along with Th and U, while the samples identified as dissolver and $1 \mathrm{AF}$ contained all the specified analytes. UST1 and UST2 samples

Dissolver solutions from irradiated thoria bundles from PHWR origin

$$
\downarrow
$$

Cs separation by CCD in FS 13 from $1 \mathrm{M} \mathrm{HNO}_{3}$

$$
\downarrow
$$

$\mathrm{U}$ and Th separation by TBP-xylene after adjustment of feed to $3 \mathrm{M} \mathrm{HNO}_{3}$

$$
\downarrow
$$

Raffinate fed to plasma for ICP-AES analysis

Fig. 5. Scheme for analysis of dissolver solutions from irradiated thoria bundles from $P H W R$. were found to contain $\mathrm{Ce}, \mathrm{Gd}, \mathrm{Nd}$, Pr, Sm, along with $U$ and Th. The analytical data obtained from these studies revealed that the $\mathrm{Nd}$ and $\mathrm{La}$ concentration values, which form the basis for computing burn-up data of the fuel bundles, were in close agreement with those obtained by the ID-TIMS technique.

\section{CONCLUSION}

An ICP-AES based method was developed for the determination of fission products in the dissolver solutions originating from irradiated thoria bundles from PHWR origin. In the first step, the ${ }^{137} \mathrm{Cs}$, which was responsible for the major gamma dose of the samples, was removed from $1 \mathrm{M} \mathrm{HNO}_{3}$ using $0.1 \mathrm{M}$ CCD in FS 13. In the second step to avoid their spectral interference, $U$ and $T h$ were removed from the samples using TBP-xylene. The ion exchange mechanism was found to be predominating with metal-ligand stoichiometry of $1: 1$ for Cs with CCD, whereas the solvation mechanism was found to be operative with metal-ligand stoichiometry of $1: 2$ and $1: 3$ for $\mathrm{UO}_{2}{ }^{2+}$ and $\mathrm{Th}^{4+}$, respectively. All the

\section{Atomic Apectroscopy \\ $\bigcirc$ Vol. 40(4), Jul./Aug. 2019}

extraction processes were found to be thermodynamically favorable as revealed from the negative $\Lambda G$ values. The $U$ and Th concentrations were determined by stripping the loaded TBP-xylene using $\mathrm{Na}_{2} \mathrm{CO}_{3}$ solution, followed by feeding into the plasma.

\section{ACKNOWLEDGMENT}

The authors wish to acknowledge the constant support of Dr. Pujari, Associate Director, Radiochemistry and Isotope Group, and Head, Radiochemistry Division, Bhabha Atomic Research Centre, Mumbai, India.

$\overline{\text { Received March 20, } 2019 .}$

\section{REFERENCES}

1. H. Eccles, Sol. Extr. Ion Exch. 18(4), 633 (2000).

2. J.N. Wilson, A. Bidaud, N.Capellan, R. Chambon, S. David, P. Guillemin, E. Ivanov, A. Nuttin and O. Meplan, Annals Nucl. Energy 36(3), 404 (2009).

3. C. Pereira and E. M.Leite, Annals

\begin{tabular}{|c|c|c|c|c|c|c|c|}
\hline \multirow[t]{2}{*}{ Elements } & \multicolumn{2}{|c|}{ Synthetic Samples } & \multirow{2}{*}{$\begin{array}{l}\text { Dissolver } \\
\left(\mathrm{mg} \mathrm{L}^{-1}\right)\end{array}$} & \multirow{2}{*}{$\begin{array}{c}1 \mathrm{CP} \\
\left(\mathrm{mg} \mathrm{L}^{-1}\right)\end{array}$} & \multirow{2}{*}{$\begin{array}{l}1 \mathrm{AF} \\
\left(\mathrm{mg} \mathrm{L}^{-1}\right)\end{array}$} & \multirow{2}{*}{$\begin{array}{l}\text { UST1 } \\
\left(\mathrm{mg} \mathrm{L}^{-1}\right)\end{array}$} & \multirow{2}{*}{$\begin{array}{c}\text { UST2 } \\
\left(\mathrm{mg} \mathrm{L}^{-1}\right)\end{array}$} \\
\hline & $\begin{array}{l}\text { Actual } \\
\text { Amount } \\
\left(\mathrm{mg} \mathrm{L}^{-1}\right)\end{array}$ & $\begin{array}{c}\text { Amount } \\
\text { Estimated } \\
\left(\mathrm{mg} \mathrm{L}^{-1}\right)\end{array}$ & & & & & \\
\hline $\mathrm{Ba}$ & 5 & $4.6 \pm 0.2$ & $3.9 \pm 0.04$ & $<0.1$ & $5.7 \pm 0.6$ & $<0.1$ & $<0.1$ \\
\hline $\mathrm{Ce}$ & 3 & $3.1 \pm 0.1$ & $6.4 \pm 0.1$ & $0.16 \pm 0.003$ & $9.0 \pm 0.3$ & $0.36 \pm 0.07$ & $0.84 \pm 0.04$ \\
\hline $\mathrm{Eu}$ & 0.2 & $0.17 \pm 0.01$ & $0.2 \pm 0.04$ & $<0.1$ & $0.28 \pm 0.01$ & $<0.1$ & $<0.1$ \\
\hline Gd & 0.5 & $0.52 \pm 0.03$ & $0.12 \pm 0.05$ & $0.44 \pm 0.08$ & $0.32 \pm 0.05$ & $1.4 \pm 0.04$ & $3.2 \pm 0.06$ \\
\hline $\mathrm{La}$ & 2 & $1.8 \pm 0.2$ & $3.3 \pm 0.03$ & $<0.1$ & $4.8 \pm 0.04$ & $<0.1$ & $<0.1$ \\
\hline Mo & 2 & $2.0 \pm 0.2$ & $2.5 \pm 0.5$ & $<0.1$ & $9.4 \pm 0.4$ & $0.32 \pm 0.02$ & $<0.1$ \\
\hline $\mathrm{Nd}$ & 5 & $5.1 \pm 0.4$ & $9.6 \pm 0.2$ & $<0.1$ & $15 \pm 0.7$ & $<0.1$ & $0.24 \pm 0.03$ \\
\hline $\operatorname{Pr}$ & 2 & $1.9 \pm 0.1$ & $3.0 \pm 0.1$ & $<0.1$ & $4.9 \pm 0.09$ & $0.24 \pm 0.1$ & $0.24 \pm 0.1$ \\
\hline Sm & 1 & $1.08 \pm 0.08$ & $1.8 \pm 0.05$ & $<0.1$ & $2.6 \pm 0.1$ & $0.8 \pm 0.05$ & $1.6 \pm 0.02$ \\
\hline $\mathrm{Sr}$ & 2 & $2.07 \pm 0.08$ & $3.4 \pm 0.06$ & $<0.1$ & $5.1 \pm 0.1$ & $<0.1$ & $<0.1$ \\
\hline $\mathrm{Y}$ & 2 & $1.92 \pm 0.05$ & $1.8 \pm 0.1$ & $<0.1$ & $2.9 \pm 0.1$ & $<0.1$ & $<0.1$ \\
\hline Th & 5 & $4.8 \pm 0.2$ & $12350 \pm 180$ & $70 \pm 1$ & $23450 \pm 700$ & $16 \pm 0.8$ & $9.0 \pm 0.7$ \\
\hline $\mathrm{U}$ & 10 & $9.5 \pm 0.6$ & $133.21 \pm 0.07$ & $109.8 \pm 0.3$ & $167.6 \pm 0.8$ & $300.6 \pm 0.6$ & $600 \pm 2$ \\
\hline
\end{tabular}

\section{TABLE IV}

Analytical Data Obtained by ICP-AES Analysis of Dissolver Solution 
Nucl. Energy 25(12), 937 (1998).

4. P. R. Kastena, Disarmament and Nonproliferation Initiatives 7(3), 237 (1998).

5. M. Lung and O. Gremm, Nucl. Eng. Design 180(2), 133 (1998).

6. A. Nuttin, D.Heuer, A. Billebaud, R. Brissot, C. Le Brun, E.Liatard, J. M. Loiseaux, L. Mathieu, O. Meplan, E. Merle-Lucotte, H. Nifenecker, F. Perdu and S. David, Prog. Nucl. Energy 46(1), 77 (2005).

7. A. Galperin, P. Reichert and A. Radkowsky, Disarmament and Nonproliferation Initiatives 6(3), 265 (1997).

8. V. C. Adya, A. Sengupta, S. K. Thulasidas and V. Natarajan, J Radioanal. Nucl. Chem. DOI: 10.1007/s10967-015-4222-2 (2015).

9. A. Sengupta, S. K. Thulasidas and V. Natarajan, J. Radioanal. Nucl. Chem. DOI: 10.1007/s10967-0143679-8.(2014).

10. T. G. Bangia, B. A.Dhawale, V. C. Adya and M. D.Sastry, Fresenius J. Anal. Chem, 332, 802 (1988)

11. A. Sengupta, V. C. Adya and S. V. Godbole, J. Radioanal. Nucl. Chem. 292(3), 1259 (2012).

12. A. Sengupta, V. C. Adya, T. K. Seshagiri and S. V. Godbole, At. Spectrosc. 34(2), 53 (2013).

13. R. K. Malhotra and K. Satyanarayana, Talanta 50(3), 601(1999).

14. S. Marin, S. Cornejo, C. Jara and N. Duran, Fresenius' J. Anal. Chem. 355(5-6), 680 (1996).

15. A. Sengupta, T. Ippili, Sk. Jayabun, M. Singh and S. K. Thulasidas, J. Radioanal. Nucl. Chem., DOI: 10.1007/s10967-016-4790-9 (2016).

16. C. Mahan, S. Bonchin, D. Figg, D. Gcrth and C. Collier, J. Anal. At. Spec. 15(8), 929 (2000).

17. M. Gopalkrishnan, K. Radhakrishnan, P. S. Dhami, V. T. Kulkarni, M. V. Joshi, A. B. Patwardhan and J. N. Mathur, Talanta 44(2), 169 (1997)

18. R. Ko, Appl. Spectrosc. 38(6), 909 (1984)

19. A. Sengupta, M. J. Kulkarni, S. V.
Godbole, V. Natarajan and P. N. Pathak, At. Spectrosc. 35(2), 60 (2014).

20. A. Sengupta, M. J. Kulkarni and S. V. Godbole, J. Radioanal. Nucl. Chem. 289 (3), 961 (2011).

21. V. N. Romanovskiy, I. V. Smirnov, V. A. Babain, T. A. Todd, R. S. Herbst, J. D. Law and K. N. Brewer, Sol. Extr. Ion Exch. 19(1), 1 (2001).

22. P. K. Mohapatra, A. Bhattacharyya and V. K. Manchanda, J. Hazard. Mat. 181 (1-3), 679 (2010).

23. P. R. Zalupskia, R. S.Herbst, L. Del Martin, D. R. Peterman and K. L. Nash, Solv. Extr. Ion Exch. 28 (2), 161 (2010).

24. A. Sengupta, V. C. Adya, P. K. Mohapatra, S. V. Godbole and V. K. Manchanda, J. Radioanal. Nucl. Chem. 283, 777 (2010).

25. A. Sengupta, V. C. Adya, M. Kumar, S. K.Thulasidas, S. V.Godbole andV. K. Manchanda, At. Spectrosc. 32(2), 49 (2011).

26. P. K. Mohapatra, A. Sengupta, M. Iqbal, J. Huskens and W. Verboom, Inorg. Chem. 52(5), 2533 (2013).

27. P. K. Mohapatra, A. Sengupta, M. Iqbal, J. Huskens and W. Verboom, Chem. Eur. J. 19(9), 3230 (2013). 